\title{
Consumer savings, price, and emissions impacts of increasing demand response in the Midcontinent electricity market
}

\author{
Authors: Steve Dahlke ${ }^{\mathrm{a}, \mathrm{b}}$ and Matt Prorok ${ }^{\mathrm{a}}$ \\ February 12, 2019 \\ a Great Plains Institute, $280121^{\text {st }}$ Ave, Suite 220, Minneapolis, MN 55407 \\ ${ }^{b}$ Colorado School of Mines, Division of Economics and Business, Golden, CO 80401
}

\begin{abstract}
This paper estimates consumer savings, $\mathrm{CO}_{2}$ emissions reductions, and price effects from increasing demand response (DR) dispatch in the Midcontinent Independent System Operator (MISO) electricity market. To quantify market effects, we develop a dynamic supply and demand model to explore a range of DR deployment scenarios. The study is motivated by the existence of regulatory and market rule barriers to market-based deployment of DR resources in the MISO region. We show annual consumer savings from increased market-based DR can vary from $\$ 1.3$ million to $\$ 17.6$ million under typical peak operating conditions, depending on the amount of DR resources available for market dispatch and the frequency of deployment. Consumer savings and other market effects increase exponentially during atypical periods with tight supply and high prices. Additionally, we find that DR deployment often reduces $\mathrm{CO}_{2}$ emissions, but the magnitude of emissions reductions varies depending on the emissions content of marginal generation at the time and location of deployment. The results of this study suggest regulators and other stakeholders should focus policy efforts to reducing regulatory barriers to DR deployment in wholesale markets, particularly in locations that experience high price spikes, to improve market efficiency and achieve cost savings for consumers.
\end{abstract}

Keywords: Energy Economics, Energy Policy, Demand response, Electricity markets JEL codes:

D22 Microeconomics: Production and Organizations: Firm Behavior: Empirical Analysis L94 Industrial Organization: Industry Studies: Transportation and Utilities: Electric Utilities L98 Industrial Organization: Industry Studies: Transportation and Utilities: Electric Government Policy

Q41 Energy: Demand and Supply - Prices

Q48: Energy: Government Policy 


\section{Introduction}

A significant challenge associated with the development of wholesale electricity markets is the lack of demand-side participation. In most electricity markets, consumers face static prices that often do not change over the course of days, weeks, and months, while the costs to supply electricity change significantly across these time scales. The result is a mismatch between realtime market conditions and retail prices that causes over-consumption during high-price periods and under-consumption during low-price periods (Schweppe, Caramanis, Tabors, \& Bohn, 1988; Faruqui \& George, 2002). This inefficiency increases spot price volatility, makes it more difficult for operators to manage physical constraints, and increases vulnerability to the exercise of market power (Bushnell, Hobbs \& Wolak, 2009). In the MISO region there is a significant potential for electricity demand response that is largely unmet (Faruqui, Hajos, Hledik, \& Newell, 2009). Barriers in the region include state regulatory hesitancy and wholesale market rules designed for large centralized power generation (Cappers, MacDonald, Goldman, $\& \mathrm{Ma}, 2013)$. These regulatory barriers keep economic demand response resources out of the wholesale energy market, creating an inefficiency that leads to artificially high prices.

This paper quantifies wholesale consumer savings and other impacts of increasing economic demand response (DR) dispatch in the MISO energy market using a bottom-up ${ }^{1}$ hourly supply and demand model for the Midcontinent Independent System Operator wholesale electricity market (also referred to as Midcontinent ISO, or MISO; in the remainder of the paper we will use the acronym MISO). The MISO market spans 15 U.S. states and facilitates trade across 65,000 miles of electric transmission and between 200 gigawatts of electricity generation. We model DR dispatch across three different MISO subregions, North, Central, and South, defined in Figure 1 (MISO, 2014).

\footnotetext{
1"Bottom-up" means we rely on historic generator-level and DR program data to build supply curves, and historic demand data to construct demand curves. Conversely, a "top-down" modeling approach may involve constructing a model using market-wide summary statistics and representative technical and cost assumptions. See Rivers \& Jaccard (2005) for further discussion of differences between top-down and bottom-up modeling approaches in the context of energy modeling.
} 


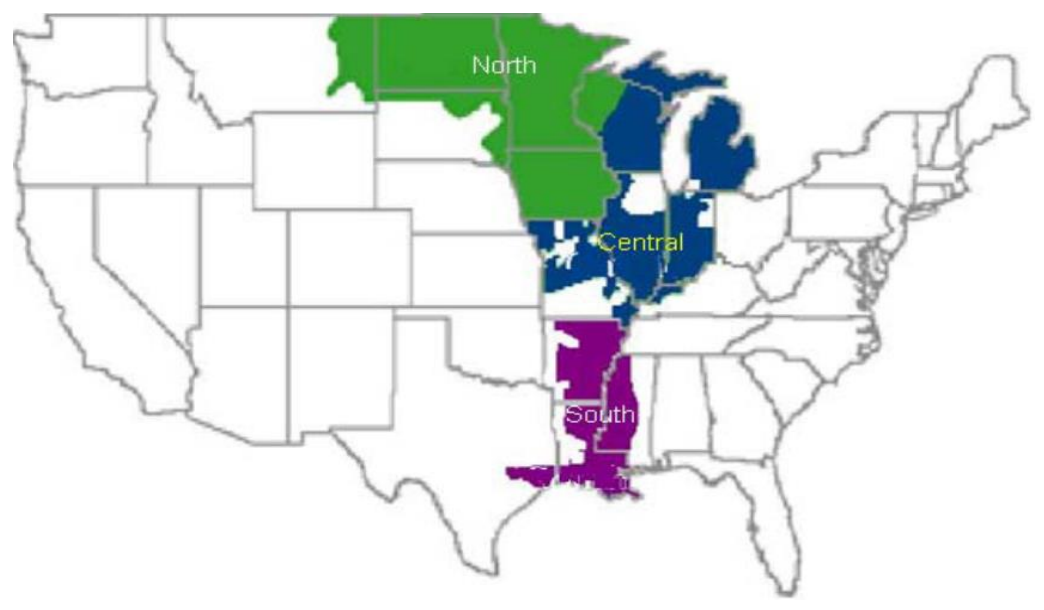

Figure 1 MISO market and subregions.

We use historic data to simulate market effects from dispatching a range of existing DR resources that are currently out of the market. All datasets and code for this analysis, as well as online appendices, are publicly available on the Open Science Framework repository available at https://osf.io/6r5cw/. Our study is not the first to show energy market benefits from increased DR (e.g. see Faruqui, Hledik, Newell, \& Pfeifenberger, 2007; Walawalkar, Blumsack, Apt, \& Fernands, 2007; Braithwait \& Eakin, 2002; Aalami, Moghaddam, \& Yousefi, 2009). However, as discussed in Cappers et al. (2013), DR in the MISO market is shaped by a unique set of state-jurisdictional regulatory and market rule challenges that do not exist in other competitive wholesale markets, warranting a region-specific study. We make several contributions to the literature. First, we estimate market effects from increased DR dispatch for the MISO market, the largest power system in the United States by geographic scope and one of the largest electricity markets in the world. Second, we fill a gap in the energy literature characterized by a lack of studies on incentive-based DR. Third, we apply microeconomic theory to model the costs and benefits of dispatching incentive-based DR in a wholesale electricity market using a net-benefits criteria, described in section 2.2. Finally, we combine DR data from the U.S. Energy Information Administration (EIA) with ISO market data in a dynamic supply and demand simulation model. Other novel characteristics of this study include estimating wholesale DR market offers from EIA data, calculating the sensitivity of results to a range of DR energy shifting assumptions, and producing estimates of carbon emissions impacts for various DR deployment scenarios.

The rest of this paper is organized as follows. In section 2 we define and classify DR for the purposes of our analysis, and motivate our research design and modeling strategy. In section 3 we describe the methodology and data used for the analysis. In section 4 we present our results, and in section 5 we conclude with a summary of results and subsequent policy recommendations. Our modeling shows how increasing cost-effective DR dispatch can generate 
consumer savings net of system costs by lowering prices under typical peak operating conditions. We also show how the market impacts of DR increase exponentially when deployed during critical peak operating conditions.

\section{Motivation}

\subsection{Background}

Demand response in electricity markets encompasses a range of market participant activities, programs, and technologies. DR can be classified into two broad categories, according to definitions adopted by the U.S. Department of Energy, the Federal Energy Regulatory Commission (FERC), and numerous academic articles (U.S. DOE, 2006; U.S. FERC, 2009; Albadi \& El-Saadany, 2008). The first category of DR is defined as "changes in electricity usage by end-use customers from their normal consumption patterns in response to changes in price." These types of demand response resources are referred to as price-based programs, and encompass electricity price structures designed to change over time including time-of-use (TOU), criticalpeak-pricing (CPP), and real-time-pricing (RTP) programs. The second category is defined as "incentive payments designed to induce lower electricity use at times of high wholesale market prices or when system reliability is in jeopardy." These resources are referred to as incentivebased programs and include direct load control (DLC) and interruptible/curtailable (I/C) load programs.

The MISO region of the United States historically has had a higher proportion of DR relative to total load compared to other regions in the United States for several important reasons. First, some states in the region require utilities to invest a percentage or two of revenue from retail sales in DR programs. Second, utilities in the region have historically had favorable resource adequacy rules that allow load management to be counted towards meeting reserve requirements, generating savings or revenues from the DR even if it is never deployed. Third, the customer base in this region has a significant fraction of industrial load that is amenable to interruption (Cappers, Goldman, \& Kathan, 2009). EIA reports that utilities in MISO have 4.4 GW of DR (U.S. Energy Information Administration, 2016), while MISO reports they have 5.7 GW of DR resources available (MISO Planning Resource Auction, 2016). This discrepancy is largely due to the fact that EIA's DR survey form covers electric retail utilities, and not large end-use customers that register their DR program directly with MISO.

Despite a large portion of DR in the MISO region, the resources are deployed at a much lower frequency than the rest of the country. For example, in 2015 only $22 \%$ of the available DR resources in the MISO market were deployed, compared to $42 \%$ in the rest of the country (U.S. EIA, 2016). In California, a particularly active market for DR, $64 \%$ of available resources were 
deployed. During the few occasions when DR resources in the MISO are deployed, they are often done so by individual utilities outside of the MISO market, and show up to the market operator as unexpected load reductions. However, the large majority of DR is available for direct deployment by MISO up to at least 5 times per summer through a product category called a "Load Modifying Resource" (LMR). LMRs do not directly participate in the energy market and are only called on during grid emergencies. However, many LMR resources are "economic" during peak periods in that they have a lower marginal cost of dispatch than the generators in the energy market that get dispatched ahead of them. MISO has an energy DR program available but participation is negligible due to market rule and regulatory barriers.

MISO has historically underutilized the DR assets available to it. Since the launch of MISO's energy markets in 2005, MISO has only deployed its registered DR under the LMR asset classification twice at the time of writing. On April $4^{\text {th }}, 2017$ during a maximum generation event triggered by unseasonably high temperatures, MISO called on just over 700 MWs of LMRs in the southern portion of its footprint (MISO LMR Performance, 2017). The only other deployment in MISO's history we have record of was in 2006 (Potomac Economics, 2017).

Various market and state regulatory barriers prevent better DR participation in the MISO market. MISO's rules for economic Demand Response Resources require a minimum size threshold of at least 1 megawatt to participate in the market ${ }^{2}$ (MISO Tariff, 2017; MISO BPM, 2016). Additionally, MISO's rules make it difficult to aggregate small DR resources to meet the minimum size threshold. ${ }^{3}$ This prevents many demand response resources from entering the market. Other markets that have more active DR participation, including PJM and ISO New England, have corresponding minimum size thresholds of $0.1 \mathrm{MW}$ and do allow aggregation of resources across pricing nodes. The second reason for low DR participation in MISO is state regulatory resistance to giving up control of regulated DR assets in the competitive market. As a result, regulators often will not let utilities enter their DR assets into the wholesale markets, and most states in the MISO region have banned commercial activity by third party DR aggregators (Cappers et al. 2013). More information on regulatory and technical reasons why

\footnotetext{
${ }^{2}$ In order for any resource to set prices in the market it must be both eligible to provide specific market services and be included in MISO's Network Model. Demand Response Resources (DRR) - Type II must be at least 1 MW to be included in the Network Model. DRR-Type I do not have this same requirement, but are only modelled as load in the Network Model and thus are not able to set market clearing prices. Instead they may only participate as a price taker.

${ }^{3}$ For DR providing energy and reserve services, MISO prevents aggregation across local balancing authority areas, and for DR providing regulation service, MISO presents aggregation across economic pricing nodes.
} 
demand-side management programs have underdelivered in wholesale electricity markets around the world are provided by Wirl (2000) and Rivers \& Jaccard (2011).

\subsection{Modeling DR in wholesale markets}

In this section we develop a general microeconomic model that is applied to understand the effects of deploying incentive-based DR in a wholesale electricity market under a net-benefits criterion. First, it is important to clarify that consumers in the wholesale market are often electric utilities or third-party intermediaries purchasing energy on behalf of their customers. In some cases, large users of electricity will bypass the utility and purchase energy directly from the wholesale market. All these entities can provide demand response in the wholesale market. ${ }^{4} \mathrm{~A}$ utility demand response program in the wholesale market is typically an aggregation of the utility's customers who are able to provide reliable energy reductions when it is costeffective to do so. The details of the financial arrangements between utilities and their retail customers, including incentives offered to DR consumers for participation, as well as what happens with the wholesale revenue earned by the utility, are not included in our model. These retail arrangements can vary by utility and customer, they occur downstream of the wholesale model, and are out of scope for this study. In the model we assume a competitive wholesale market so that DR resources offer into the market at the marginal cost of energy reduction. This includes the cost to the consumer of not using the electricity, plus marginal costs associated with administering the energy reduction. In reality, market participants may violate this assumption by acting non-competitively or may be constrained from acting competitively by regulations.

Aggregate wholesale electricity demand is inelastic to the wholesale price and a function of an exogenous fixed retail price $P_{r}$ and a demand shifting parameter $A_{t}$, represented by $D\left(P_{r}, A_{t}\right)$. $A_{t}$ varies exogenously through time due to external factors such as weather and changing consumer preferences. We assume generators are competitive and offer into the market until price falls below their marginal cost of production. $S_{t}(P, \bar{K})$ provides the aggregate market supply at price $P$ with total supply capacity $\bar{K}$. The quantity cleared in the market is equal to the amount demanded at the fixed retail price $P_{r}$, so that $Q=D\left(P_{r}, A_{t}\right)$. If generators are stacked by their marginal cost so that the lowest-cost generator is deployed first, the wholesale market clearing price is determined by the marginal cost of the last generator required to meet market demand $Q$, so that $Q=S\left(P_{w}, \bar{K}\right)$. In the short term, $Q$ is inefficiently high when $P_{w}>P_{r}$, and inefficiently low when $P_{w}<P_{r}$, generating dead-weight loss (DWL).

\footnotetext{
${ }^{4} \mathrm{~A}$ utility may also contract with another entity to aggregate customers and offer DR into the market on their behalf.
} 
Incentive-based DR programs involve payments to customers in exchange for energy reductions. Current federal regulations in the United States require DR in wholesale markets to be compensated the same as electric generators providing a similar energy service (U.S. Federal Energy Regulatory Commission, 2011). An incentive-based DR deployment in the market can be modeled by a leftward shift in the market demand curve to $D\left(P_{r}, A_{t}\right)-D R$ as shown in Figure 2. Now the market clearing quantity is $Q_{2}=Q_{1}-D R$, and the new wholesale price $P_{w 2}$ is equal to the marginal cost of the last generator needed to supply $Q_{2}$. The price reduction generates consumer savings equal to $Q_{2} \times\left(P_{w 1}-P_{w 2}\right)$. Since regulations require that $\mathrm{DR}$ providers be compensated at the wholesale price, there are still $Q_{1}$ resources receiving payment $P_{w 2},{ }^{5}$ but only $Q_{2}$ electricity consumers purchasing at $P_{w 2}$. This creates a market revenue shortfall equal to $P_{w 2} \times\left(Q_{1}-Q_{2}\right)$, the revenue owed to DR providers (labeled "DR Revenue" in Figure 2 ).

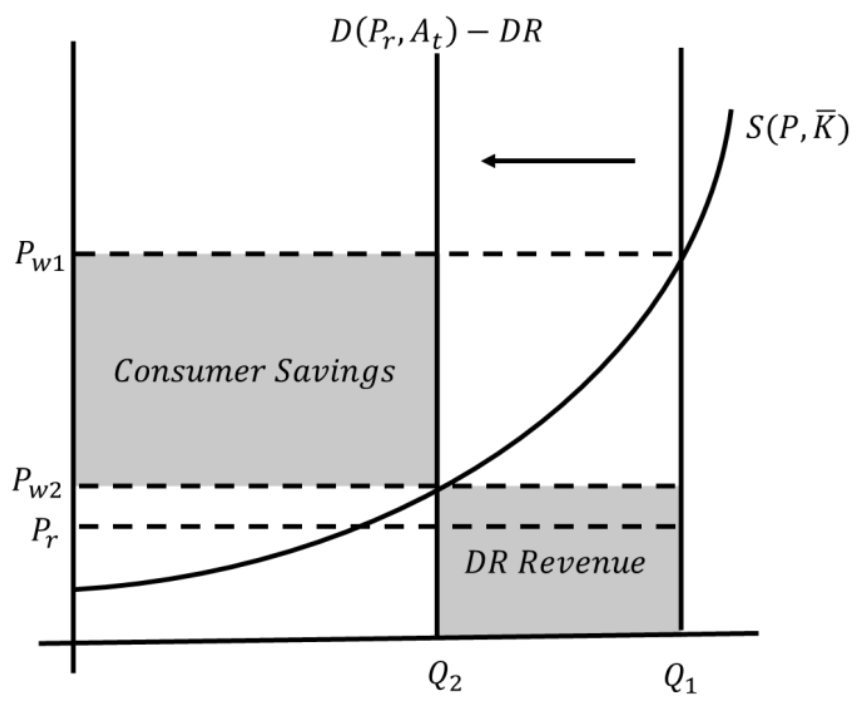

Figure 2 Incentive-based DR deployment modeled as a shift in demand.

The fact that consumer savings from DR deployment are offset by the revenue owed to DR providers is known as the billing effect. The revenue shortfall is typically socialized as a charge applied proportionately to the remaining wholesale consumers. If DR revenue exceeds consumer savings, costs will outweigh the benefits of DR deployment. FERC regulations require that consumer savings be greater than revenue to DR consumers, so that non-DR consumers still experience a net-benefit from DR deployment. The situation in which consumer savings equals DR revenue is known as the net-benefits threshold, below which DR cannot be deployed (FERC, 2011). Any demand reduction that occurs when the market equilibrium is at an inelastic portion of the supply curve will yield more consumer savings then revenue owed to DR owners

${ }^{5}$ This consists of $Q 1-Q 2$ DR resources and $Q_{2}$ generation resources receiving $P_{w 2}$. 
and pass the net benefits test. Our analysis is designed to ensure that all DR deployments that occur in the simulations satisfy the net benefits test.

Because incentive DR programs are compensated at the wholesale price like a generator, market operators treat DR like generators in that they are dispatched as part of the supply stack. In this case, DR dispatch can be equivalently modeled as a rightward shift in supply, shown in Figure 3. In this model, DR resources prior to being dispatch are equivalent to negative supply, so the original supply curve is left of the market supply curve presented in Figure 2. $Q_{1}$ is the quantity that would clear if DR was not included as a supply resource and instead added back to the demand curve. $Q_{2}$ is the market clearing quantity with DR included. Since in this case DR is scheduled as supply, $D\left(P_{r}, A_{t}\right)$ does not include the demand reserved as DR capacity. As in the previous case, consumer savings are equivalent to $Q_{2} \times\left(P_{w 1}-P_{w 2}\right)$, and the revenue owed to DR providers is equal to $P_{w 2} \times\left(Q_{1}-Q_{2}\right)$.

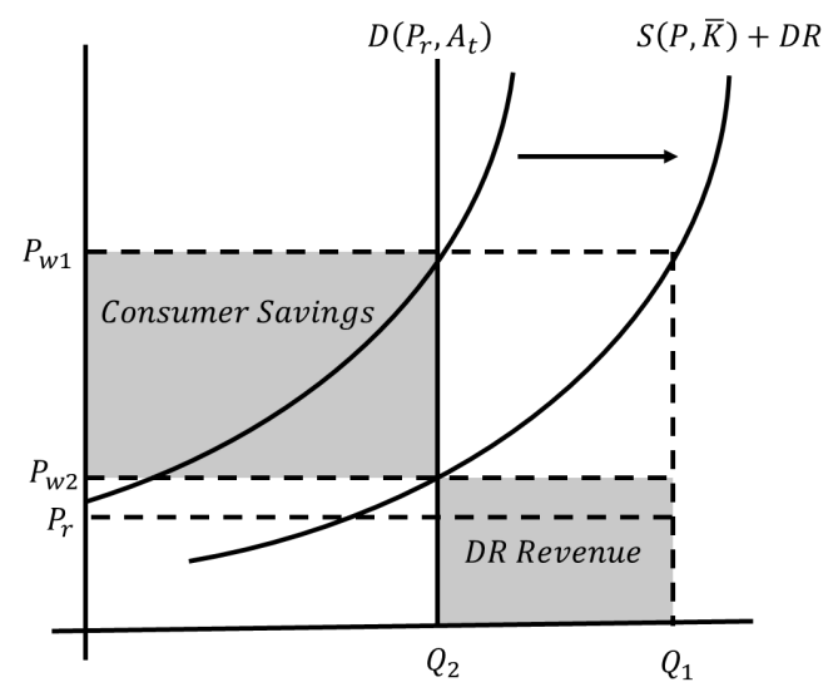

Figure 3 Incentive-based DR deployment modeled as a shift in supply.

\subsection{Why model incentive-based DR?}

Most incentive-based DR programs in the U.S. were developed starting in the 1980's due to a significant increase in air-conditioning load, which increased the need for peaking capacity relative to non-peak. Many regulated utilities invested in incentive-based DR as a lower-cost alternative to peaking generators (Lovins, 1985). At the time, metering technology required to implement price-based DR was not available. After significant incentive-based DR investments in the 1980's and 1990's, the FERC assumed jurisdiction via a congressional mandate and began working to remove barriers to DR participation in wholesale markets (Wellinghoff \& Morenoff, 2007). Now, advanced metering technology to enable price-based DR is available, however the prevalence of price responsive demand remains small primarily due to an unwillingness by state regulators to expose retail customers to uncertain prices (Bushnell et al. 2009). 
Economists disagree on the effectiveness of compensating incentive-based DR at the wholesale price as current regulations require. Some claim that wholesale payments for energy reductions inflate price signals because customers are 'double-compensated' for their reduction, as DR participants benefit both from the savings from not purchasing electricity and the wholesale market payment (Hogan, 2010). Others worry that incentive-based DR will crowd out true price response (Bushnell et al. 2009). Additionally, they point out incentive-based DR consumers may game the market and inflate pre-reduction consumption baselines if proper rules are not implemented, (Chao \& Depillis, 2013; Chen \& Kleit, 2016). Some do note that concerns about improper baselines can be mitigated by properly structured market rules, as outlined by Chao \& Depillis (2013).

Proponents of incentive-based DR in wholesale markets point out it is a second-best solution that, in the absence of price-responsive demand, moves market prices closer to the efficient level. Additionally, implementing a price-based DR program includes upfront costs that in many cases exceed the benefits to the customer (Leautier, 2014). In a market with static retail rates, failing to deploy DR resources when the market clearing price exceeds the marginal cost of demand reduction results in a market inefficiency (Kahn, 2010). This is the case in the MISO market, leading to inefficiently high prices and extra costs for consumers. Moreover, there is a gap in the literature with respect to studies on incentive-based DR. A recent literature review analyzed 117 studies on DR modeling, and concluded:

there is a clear lack of models addressing incentive-based DR programs. This is somewhat astonishing given the fact that, in the U.S., DLC and I/C programs are applied more frequently than TOU or RTP programs. The majority of studies focus on pricebased programs (Boßmann \& Eser, 2016).

Furthermore, there is currently a large fleet of underutilized incentive-based DR assets in the MISO region that are not comprehensively integrated into the wholesale energy market, described previously in section 2.1. Despite concerns from some economists with respect to incentive-based DR, we analyze effects of increasing participation of incentive-based DR in the MISO market because, 1 ) there is a much bigger penetration of incentive-based DR currently in existence relative to price-based DR, 2) these resources are underutilized and not comprehensively integrated into wholesale markets, especially in MISO, and 3) there is a lack of studies in the literature focused on incentive-based DR. 


\section{Methodology}

\subsection{Overview}

The purpose of our modeling exercise is to estimate consumer savings, emissions impacts, and price effects from increasing DR dispatch in the MISO energy market. We do this for a range of scenarios that explore differences in DR dispatch amounts, frequencies, energy shifting effects, and energy offer prices. Our modeling approach consists of a dynamic supply and demand model that varies hourly, where the market clearing prices and quantities are determined by the intersection of the two curves. This is similar to the model applied in Buzoianu, Brockwell, \& Seppi (2005), except in our case supply curves are constructed bottom-up from historical generator-level offers data obtained from MISO. Demand curves in the model are based off hourly historic MISO demand data and are assumed to be inelastic. We assume inelastic demand because the large majority of electricity customers in the MISO region face retail rates that are fixed in the short-term and do not adjust when wholesale prices change. We use 2015 market and DR data because it is the most recent year in which demand response data is available from the EIA at the time of writing. Additionally, real-time instead of day-ahead MISO market data are used since the real-time market is used as a 'true-up' to balance unexpected deviations from day-ahead predictions and scheduling. Furthermore, real-time prices more accurately reflect historic system conditions, and are the final prices used to settle transactions in the energy market. Because our bottom-up supply curves are discontinuous, we use an iterative solver-based approach to calculate the market equilibrium for each hour and market region, programmed in the $\mathrm{R}$ statistical computing language. We model supply and demand for every hour of 2015 for the three MISO regions defined in Figure 1: North, Central, and South. This is motivated by recent empirical work finding sub regional variation in price responsiveness within the MISO region (Eryilmaz, Smith, \& Homans, 2017). Our analytical approach quantifies market clearing price and quantity effects from dispatching DR and compares them to baseline outcomes that occurred without DR.

The model scenarios dispatch DR based on resource quantities and marginal cost estimates for existing DR resources located in the MISO region that do not participate in the energy market. ${ }^{6}$ Since most DR resources in the MISO region are registered through the market under the 'Load Modifying Resources' (LMR) category, our model dispatch constraints are based on MISO's LMR operating agreement (Potomac Economics, 2017). LMR contracts require DR resources to be available for up to 5 deployments during the summer season for a minimum of 4 hours per deployment (MISO Tariff, 2017). Because many DR programs are available for dispatch more

\footnotetext{
${ }^{6}$ Except for the few events described in section 2.1 .
} 
than 5 deployments per year and not necessarily limited to summer months ${ }^{7}$, we simulate additional scenarios that dispatch DR up to 20 times per year and outside of summer months when it is economic to do so.

Since the number of DR deployments per year is constrained, DR should be deployed on days with both high prices and energy demand in order to maximize value. To determine the highest value days in 2015, we use a similar approach to The Brattle Group (2007) and rank highest value days according to the price-load product for 4-hour dispatch blocks. Specifically, we multiply the average price and demand for each hour in 2015 and calculate 4-hour moving averages. We then select the days that have the highest priceload product average to determine the most valuable days for DR dispatch, eliminating duplicate days. Because we model scenarios that limit DR dispatch to summer months as well as scenarios that model DR dispatch year-round, we compile two lists of 20 highestvalue days from 2015, one for the entire year and the other restricted to the summer month. These lists are provided in online appendix 1, publicly available at the link provided in section 1 .

\subsection{Costs}

A key input for the supply-demand model is resource-level energy offers, measured in dollars per megawatt-hour (\$/MWh). These are the supply offers from which the market operator schedules least cost dispatch. In section 2 we describe that market rule and regulatory barriers currently inhibit a competitive DR market in MISO. In contrast, our modeling effort is designed to explore the effects of a more competitive market. In a competitive market, DR is assumed to offer energy reductions at the marginal cost of deployment. In the absence of marginal cost data, DR energy offers are estimated to be a function of the cost incurred by the underlying electricity customers for service interruption, which varies by customer. ${ }^{8}$ To estimate DR energy offers, we use utility-reported data from the EIA on DR customer incentive costs. Customer incentive costs are defined as the total financial value provided to a customer for their program participation, including direct payments, lowered tariff rates, in-kind services, or other benefits (U.S. EIA, 2014). Customers that have a high cost of electricity interruption will demand high incentive payments, and have a lower likelihood of deployment (Albadi \& ElSaadany, 2008). The distribution of energy offer estimates is displayed in Figure $4.3 \%$ of MISO DR programs had offer cost estimates above $\$ 200 / \mathrm{MWh}$, which are omitted from the figure to eliminate scaling issues, a portion of these were at the offer cap of $\$ 2000 / M W h$. As shown in

\footnotetext{
${ }^{7}$ Cappers et al. (2013) notes that incentive-based DR programs have historically been designed for between 8-20 deployments per year.

${ }^{8}$ For example, a hospital may have a greater cost of electricity interruption than an office building.
} 
the chart, about one third of MISO DR resources have low energy offer estimates between $\$ 0 / \mathrm{MWh}$ and $\$ 10 / \mathrm{MWh}$. The remaining distribution is spread about evenly between $\$ 10 / \mathrm{MWh}$ and $\$ 200 / M W h$. Further details on the DR energy offer estimation methods are provided in online appendix 2.

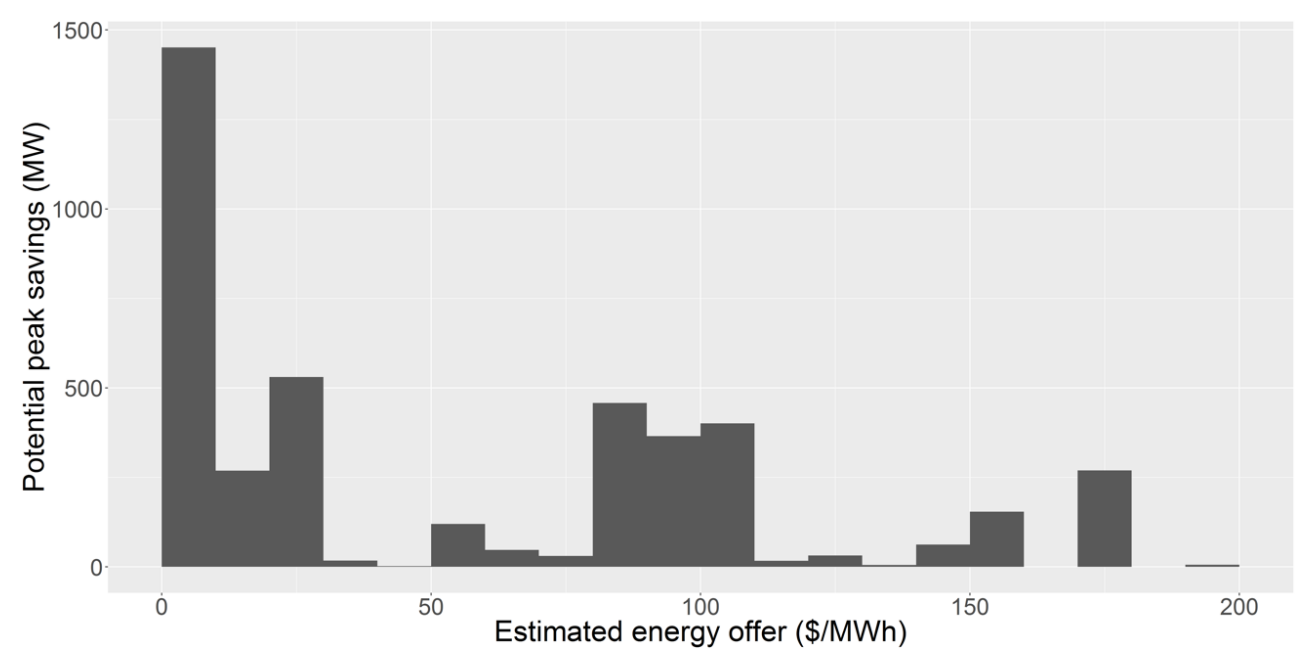

Figure 4 DR resource by estimated energy offer, MISO region.

Our energy offer estimates are compared to historic DR offers in the PJM market, which has active energy market DR participation. In 2015, economic demand response resources in the PJM market provided over 121,000 MWhs of supply (McAnany, 2016). Demand response bids during this year range between $\$ 0 / \mathrm{MWh}$ and $\$ 1,850 / \mathrm{MWh}$. This range aligns well with the range of our marginal cost estimates, however the PJM DR offers are higher on average (McAnany, 2016). This could be due to a number of factors, including higher costs of DR deployment in PJM compared to MISO, non-competitive bidding behavior by DR providers, or under-estimated DR program costs provided by utility survey responses to the EIA. Due to higher energy offers from DR observed in PJM, we model sensitivity scenarios in which all energy offers in MISO are increased by $100 \%$.

\subsection{Baseline model}

Hourly supply curves were constructed using historic MISO offers data. This data includes hourly price-quantity pairs for every generator offering into the MISO, anonymized to protect confidentiality. From this we construct hourly supply curves by region. We separate the model into MISO's three operations regions: North, Central and South. Inelastic demand is included based on historic load data, and the intersection of supply and demand curves determines the market clearing price and quantity prediction for each hour and region. As an example, Figure 5 plots the supply and demand curves for the North region on July 12, 2015 at 4pm. 


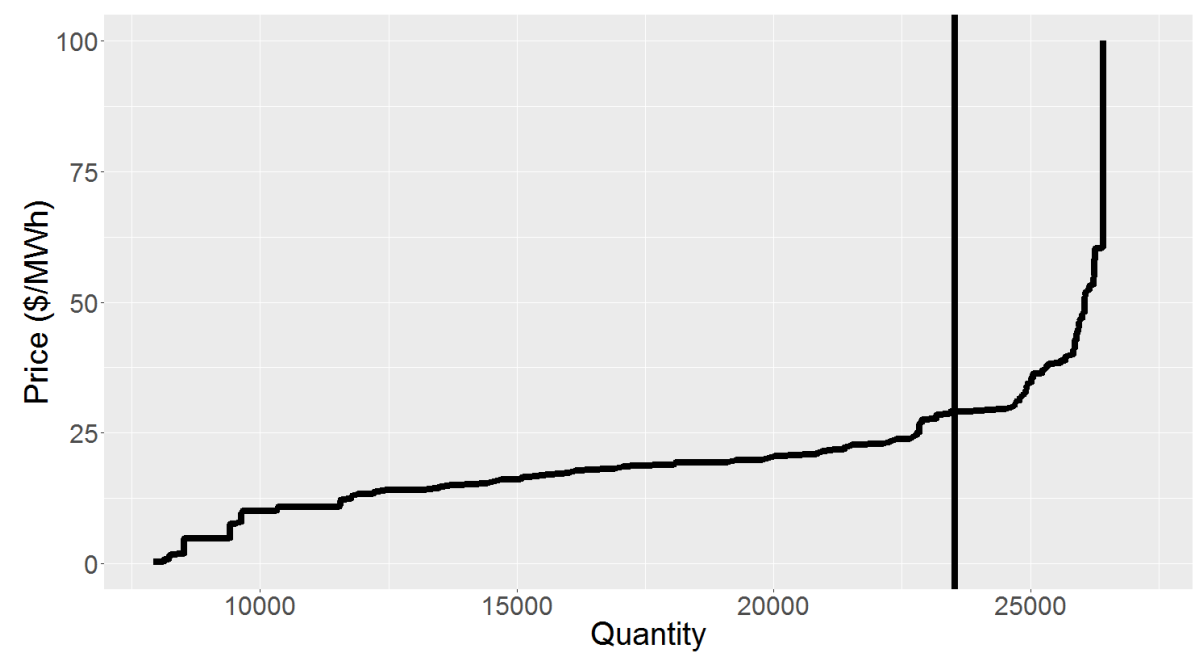

Figure 5 MISO system supply curve plus demand (vertical line) for the North region on July 12, 2015 at $4 \mathrm{pm}$.

Next, DR resources are added to the baseline model, assigning each DR resource to the corresponding region depending on that resource's reported state. The baseline supplydemand model predicts hourly prices based on historic data. The model abstracts from other real-world factors that also determine price, including transmission constraints, net imports, unforced outages, and forecast error. Sometimes these factors cause large price spikes that our model does not predict. To understand how often actual prices deviate from our model's predictions we compare the model-predicted prices to actual historic prices. Plots of the hourly distributions of actual prices by subregion for the highest-value days modeled are provided in online appendix 3.

Figure 6 shows the average predicted prices by hour versus average actual prices for the 20 highest value days in the south region during the summer of 2015. These hourly averages are smoothed ${ }^{9}$ and weighted by daily demand. The model consistently under predicts prices during afternoon peak hours. Corresponding plots for the North and Central regions are provided in online appendix 4. Peak periods are when factors exogenous to our model including transmission constraints and forecast error are most pronounced and when we expect the model to under-predict prices. We use historical price data to adjust the baseline model to better reflect the actual price levels throughout the day. The difference between the average actual price and the average predicted price for each region are used as hourly adjustment factors to calibrate the model's predictions. This adjusts predicted prices upward during hours

\footnotetext{
${ }^{9}$ We apply exponential smoothing to the actual hourly price series to minimize noise across hours. Hourly smoothing doesn't materially affect modeling results since DR events are modeled in 4-hour blocks.
} 
in which the model systematically under-predicts prices, and downward during hours that systematically over-predict prices.

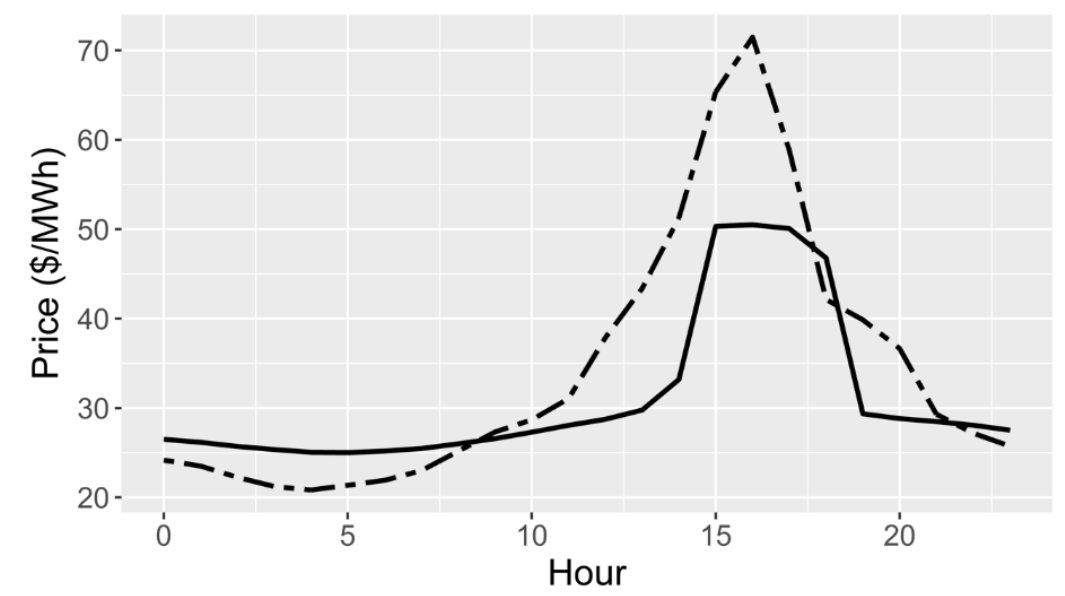

Figure 6 Average hourly prices predicted by model (solid line) versus actual prices (dashed line) during highest value summer days in 2015 , south region.

Most of our modeling results, including changes in consumer savings, emissions, and prices, are calculated as differences between scenarios with and without DR in the supply curve, all else equal. Thus, the adjustments made to absolute price levels will not directly impact these results. The adjustment factors allow for predicted market clearing prices that more closely match historic prices, and simulate levels of economic DR clearing the market based on realistic price levels.

\subsection{Energy shifting}

Aggregate effects on demand from DR dispatch consist of both a reduction and a shift in energy use. Demand shifting involves moving electricity use to off-peak periods, but doesn't involve a net reduction in energy use over time. Smith \& Brown (2015) find that on average, 16\% of peak energy reduction from DR is shifted to off-peak periods. This value was derived from pricequantity elasticity estimates from a study that empirically measured the effects of a Duke Energy real-time pricing program over 8 years (Taylor, Schwarz, \& Cochell, 2005). Modeling in De Jongh, Hobbs, \& Bellmans (2012) assumes DR energy shifting ranges from $8 \%$ to $16 \%$. Furthermore, FERC's Demand Response Impact and Value Estimation (DRIVE) model provides hourly impact profiles of DR programs. Examining the load shifting parameters in this model for residential programs, commercial/industrial (C/I) interruptible tariffs, and other large $\mathrm{C} / \mathrm{I}$ programs, yields a weighted average energy shift value of $12.1 \%$. In contrast, the EIA NEMS assumes DR energy shifting of $96 \%$, although this parameter does not appear to be supported by empirical experimental evidence (Smith \& Brown, 2015). 
Drawing from this literature, our baseline scenario assumes 15\% of DR energy reductions are shifted to off-peak hours. We also conduct sensitivity scenarios that assume 1) zero energy shifted to off-peak, and 2) $96 \%$ energy shifted to off-peak. We model DR reductions occurring during the last hour of the highest-value four-hour blocks plus the three preceding hours. The load shift is then modeled as an energy increase during the four hours following the DR reduction. In the occasional situations where DR deployment occurs during the late evening (HE 19-23), we model the rebound during the hours preceding the event, assuming customers will anticipate the DR reduction instead of increasing energy use when most people are asleep. Since prices are similar on average before and after DR events, changing whether the energy shifting occurs before or after the DR event does not have a material impact on the aggregate market effects reported as results.

\subsection{Carbon emissions}

We estimate carbon dioxide $\left(\mathrm{CO}_{2}\right)$ emissions effects for each model scenario. For confidentiality purposes, MISO's generator offers data do not identify individual plants, so neither plant-level emissions nor fuel-type information is available. We approximate the carbon content of the marginal generation for each hour by using MISO's real-time fuel on the margin data (MISO Real-Time Fuel, 2015). The data specifies the fuel of the marginal generator by region for every hour. Specifically, we multiply the hourly change in energy from DR (in MWh) by our estimate of the hourly $\mathrm{CO}_{2}$ emissions content of the marginal generator (in $\mathrm{kg} \mathrm{CO}_{2} / \mathrm{MWh}$ ). We use national averages of $\mathrm{CO}_{2}$ emissions rates per $\mathrm{MWh}$ by fuel type from the U.S. Department of Energy (U.S. DOE, 2016), provided in

Table 1. Since the MISO fuel-type data does not break out natural gas plants by combined cycle or combustion turbine, and since data on dispatch frequency by generator type in MISO is not available, the emissions factor used for natural gas is a simple average of the combined cycle and combustion turbine emissions rates. It is possible that a reduction in DR could cause the marginal fuel type to switch, however we are unable to see when this would happen given limitations in publicly available data. Thus, our results should be treated as approximations of the $\mathrm{CO}_{2}$ emissions effects from DR dispatch.

\begin{tabular}{ll}
\hline Fuel type & $\begin{array}{l}\text { Emission rate } \\
\left(\mathbf{k g ~ C O}_{2} / \mathbf{M W h}\right)\end{array}$ \\
\hline Coal & 960.6 \\
Petroleum & 743.4 \\
Natural Gas & 505.9 \\
\hline
\end{tabular}

Table 1 U.S. average carbon dioxide emission rates by fuel type. Source: US Department of Energy.

\subsection{Scenarios}


We calculate market savings, price effects, and emissions effects for several scenarios to understand how changes in several variables affect our results. The scenarios include variations on the following parameters:

a) When to deploy DR. As discussed in section 3.1, LMR contracts only require DR to be available during the summer months (June 01 - August 31), however many DR resources in MISO can be deployed outside of the summer. We model scenarios with DR deployment occurring during the highest value hours in summer months, and another with deployment during the highest value days from the entire year.

b) Frequency of deployment. As discussed in section 3.1, MISO's DR contracts only require DR to be deployed up to 5 times per year, but DR programs are often designed to be deployed more than 5 times per year. In general, incentive-based DR programs are designed for 8-20 deployments per year (Cappers et al, 2013). We model scenarios where DR is deployed 5 times per year, 10 times per year, and 20 times per year. Note that deploying a DR resource more often will lower its average energy offer value necessary to recover program lifetime costs, which will lead to reduced energy offers in a competitive market. As a result, increasing the frequency of DR deployment will lower DR offer cost estimates described in online appendix 2. As a result, increasing the frequency of DR dispatch will lower energy offer estimates, and more DR may clear at a given price.

c) Amount of DR resources. The DR dataset obtained from the EIA reports 4,355 MW of DR registered in the MISO region. In contrast, MISO's resource auction results for the 2015-16 planning year indicate 5,745 MW of installed DR capacity (MISO Planning Resource Auction, 2016). We model a baseline scenario with the 4,355 MW of DR for which we have detailed cost data, and an expanded scenario with 5,745 MW of DR. When scaling up DR to match the amount reported by MISO, we assign the DR to regions based on their relative regional shares as reported in the EIA data, displayed in Table 2, and assume energy offers for the expanded DR equal to the median values from the detailed EIA cost data. More details on the data cleaning process for this EIA dataset are provided in online appendix 5.

\begin{tabular}{lll}
\hline Region & DR (MW) & Share \\
\hline Central & 2074.0 & 0.48 \\
North & 1791.3 & 0.41 \\
South & 489.9 & 0.11 \\
Total & 4355.2 & 1 \\
\hline
\end{tabular}


Table 2 DR resources by region. Source: US Energy Information Administration.

d) Demand shift. As discussed in section 3.4, we vary the demand shifting assumption from $0 \%$, $15 \%$, and $96 \%$.

e) Marginal costs. As mentioned in section 3.2, we model scenarios in which energy offer estimates are increased by $100 \%$, due to the possibility that DR resources may offer into the market at higher prices than our estimates.

\section{Scenario summary}

In summary, the following list summarize the five parameters that are varied to produce sensitivity scenarios:

- When to deploy DR

1. Summer

2. Year-round

- Frequency of deployment

1. 5 deployments per year

2. 10 deployments per year

3. 20 deployments per year

- Amount of DR resources

1. Base $-4,355 \mathrm{MW}$

2. Expanded $-5,745 \mathrm{MW}$

- Rebound effect

1. Low $-0 \%$

2. Base $-15 \%$

3. High $-96 \%$

- Energy offers

1. Baseline estimates

2. Baseline estimates increased by $100 \%$

We vary these parameters to produce 30 simulations, the results of which are discussed next.

\section{Results}

\subsection{Baseline scenario}

The parameter levels for the baseline scenario are listed below:

- Summer-only deployment

- 5 deployments per year 
- Base-level DR resources (4,355 MW)

- Base-level rebound effect (15\%)

- Baseline energy offer estimates

The results by region are provided in Table 3. In these and subsequent results, the dollar level values are rounded to the nearest $\$ 1,000$ to provide a realistic perspective on the model's precision. The results for the North and Central regions are more indicative of 'typical' peak operating conditions, while the South region results include an extreme price event. For example, the average adjusted predicted price during the peak hours in the baseline scenario for the North and Central regions was $\$ 43.57$, and the maximum price observed was $\$ 62.56$. The South region had similar predicted price levels except for one day where prices spiked above $\$ 100$ for a few hours, at which point a small amount of DR had a large effect on prices and consumer savings. Almost 2,000 MW of DR deployment in the North and Central regions combined is predicted to produce about $\$ 1.3$ million in consumer savings in the baseline scenario. Conversely, only $45 \mathrm{MW}$ of $\mathrm{DR}$ in the south region produced $\$ 38$ million in consumer savings.

The South region outlier demonstrates how a small amount of DR can generate exponentially higher consumer savings if deployed in a location where the market is clearing in a steep portion of the supply curve. While not typical, extreme price events do happen and contribute to a large share of the value case for DR in wholesale markets. For example, from 2015 through 2017, the years for which historical system price data is readily available online at the time of writing, there were 100 hours during which the average MISO system price exceeded $\$ 100 / M W h$. Of this 12 hours were above $\$ 200 / M W h$, of which 2 hours were above $\$ 300 / M W h$ (MISO Real-Time Pricing, 2015).

In addition to consumer savings, the baseline model shows modest $\mathrm{CO}_{2}$ emissions reductions from DR, on the order of $0.3 \%-0.5 \%$ of total electric sector emissions from the MISO region. Because DR must pass the net benefits test before being deployed, the revenue paid to DR providers is less than consumer savings for each region.

\begin{tabular}{llllll}
\hline Region & $\begin{array}{l}\text { Annual } \\
\text { consumer } \\
\text { savings } \mathbf{( \$ )}\end{array}$ & $\begin{array}{l}\text { Annual } \\
\mathbf{C O}_{2} \\
\text { reduction } \\
\mathbf{( k g )}\end{array}$ & $\begin{array}{l}\text { DR cleared - } \\
\text { hourly average } \\
\mathbf{( M W )}\end{array}$ & $\begin{array}{l}\text { Annual DR } \\
\text { Revenue } \\
\mathbf{( \$ )}\end{array}$ & $\begin{array}{l}\text { Price effect - } \\
\text { hourly } \\
\text { average } \\
\mathbf{( \$ / M W h )}\end{array}$ \\
\hline North & 466,000 & $6,754,000$ & 789 & 325,000 & -0.54 \\
Central & 836,000 & $9,696,000$ & 1,163 & 511,000 & -0.43 \\
South & $37,696,000$ & 73,000 & 45 & 15,000 & -32.33 \\
\hline
\end{tabular}


Table 3 Simulation results by region - baseline scenario.

\subsection{Alternative scenarios}

As discussed in section 3.6, we explore how changes to the parameter values impact results. The effects of parameter changes are summarized in Table 4. The first row in Table 4 presents the results of the baseline scenario for the north and central regions combined. Each subsequent row presents average deviations from the baseline for each scenario, totaled across the north and central regions, holding all other model parameters constant. For example, the values in the second row indicate that increasing from 5 to 10 DR deployments per year increases annual consumer savings by $\$ 1,054,907$ on average across our simulations. We omit the outlier results from the south region to better represent effects of DR during nonemergency peak operating conditions. Including the south region results would change these results by orders of magnitude.

\begin{tabular}{|c|c|c|c|c|c|}
\hline Scenario & $\begin{array}{l}\text { Annual } \\
\text { Savings } \\
(\$)\end{array}$ & $\begin{array}{l}\text { Annual } \mathrm{CO}_{2} \\
\text { reductions } \\
(\mathrm{kg})\end{array}$ & $\begin{array}{l}\text { DR } \\
\text { cleared - } \\
\text { hourly } \\
\text { average } \\
(\mathrm{MW})\end{array}$ & $\begin{array}{l}\text { Annual } \\
\text { DR } \\
\text { revenue } \\
(\$)\end{array}$ & $\begin{array}{l}\text { Price } \\
\text { effect - } \\
\text { hourly } \\
\text { average } \\
\text { (\$/MWh) }\end{array}$ \\
\hline Baseline & $1,302,000$ & $16,450,000$ & 1,952 & 836,000 & -0.49 \\
\hline $\begin{array}{l}10 \\
\text { deployments }\end{array}$ & $+1,055,000$ & $+10,478,000$ & +838 & $+321,000$ & -0.04 \\
\hline $\begin{array}{l}20 \\
\text { deployments }\end{array}$ & $+3,319,000$ & $+33,114,000$ & +321 & $+683,000$ & -0.12 \\
\hline $\begin{array}{l}\text { Expanded } \\
\text { amount } \\
(5,745 \mathrm{MW})\end{array}$ & $+996,000$ & $+9,346,000$ & +562 & $+465,000$ & -0.22 \\
\hline $\begin{array}{l}\text { Zero energy } \\
\text { shift }\end{array}$ & $+461,000$ & $+5,548,000$ & 0 & 0 & -0.35 \\
\hline $\begin{array}{l}\text { High energy } \\
\text { shift }(96 \%)\end{array}$ & $-2,940,000$ & $-29,958,000$ & 0 & 0 & 0.80 \\
\hline $\begin{array}{l}\text { Annual } \\
\text { deployments }\end{array}$ & $+1,500,000$ & $-3,334,000$ & -151 & $+40,000$ & -0.36 \\
\hline $\begin{array}{l}\text { High energy } \\
\text { offers }\end{array}$ & $-598,000$ & $-5,767,000$ & -202 & $-290,000$ & -0.14 \\
\hline
\end{tabular}

Table 4 Average deviations from baseline results by scenario. 
Note: Values summarize the results of 30 simulations. Each column represents results for that variable in the north and central regions. The top row presents the baseline results, summed over the north and central regions. Each subsequent row presents the corresponding scenarios' average deviations from the baseline value.

To derive the values in Table 4, we estimate a regression model using the simulated results across all scenarios for the North and Central regions. The independent variables in the regression are indicator variables corresponding to each of the simulation parameters, corresponding to the rows in Table 4. Regression coefficients on categorical explanatory variables are interpreted as average deviations from the reference category. Thus, each coefficient represents an average change from the baseline DR scenario. Because these coefficients show average deviations in outcomes predicted by various modeled supplydemand equilibria, the underlying data generating process lacks a stochastic element and reporting standard errors is not informative. The coefficients from the regression corresponding to each parameter adjustment are added to the baseline results to produce the non-baseline values in Table 4. The output for all 30 scenarios provides the underlying data for these regressions and are provided in online appendix 6 . The detailed results in the appendix show that consumer savings vary across model scenarios between $\$ 1.3$ million to $\$ 17.6$ million for the North and Central regions during typical peak operating conditions. ${ }^{10}$

As reported in Table 4, increasing the frequency of deployments per year and expanding the amount of DR resources available for deployment increases annual consumer savings, $\mathrm{CO}_{2}$ reductions, DR cleared, and price reductions relative to the baseline scenario. This is logical, as one would expect an increase in DR deployment frequency or amount to increase the magnitude of market effects relative to the baseline scenario. Changing the demand shifting parameter to zero also increases the savings, $\mathrm{CO}_{2}$ reductions, and the price effect relative to the baseline scenario. This is because in the baseline scenario, the $15 \%$ demand shift partially offsets the peak hour effects as consumers purchase more energy in off-peak hours. The 'annual deployments' row indicates that allowing DR to dispatch during non-summer days when more cost savings opportunities are available will increase overall consumer savings, while the negative coefficient on emissions suggests less opportunity for emissions reductions are available during non-summer months. This is because DR deployments during summer months often reduce output from less efficient peaking generators, and DR in non-summer months sometimes shifts peak energy generated from gas to off-peak energy generated from coal. Finally, increasing DR energy offer costs by $100 \%$ reduces annual consumer savings by about one-third, decreases emissions savings, lowers the amount of DR cleared, and dampens the negative price effect relative to the baseline scenario. This is to be expected, since this scenario makes DR resources more expensive for the market operator.

\footnotetext{
10 These numbers exclude the simulations with $96 \%$ energy shifting as this is not an empirically realistic level.
} 
Excluding outliers from the South region, the results of our modeling across all our simulations show average price reductions ranging from $3 \%$ to $9 \%$. This is consistent with past analyses of the PJM market, which showed that reducing approximately $1 \%$ of peak demand in the PJM market would result 5\%-8\% reduction in LMPs (The Brattle Group, 2007; Faruqui, Hledik, Newell, \& Pfeifenberger, 2007).

The scenario with a high energy shift produced some interesting results. First, increasing the rebound effect to $96 \%$ increased overall $\mathrm{CO}_{2}$ emissions in every region and deployment scenario, suggesting that on off-peak generation in MISO has a higher average emissions content than on-peak generation. Secondly, some of our high-rebound simulations produced negative net consumer savings. In other words, deploying demand response resources that pass the net benefits test in the hour they were deployed actually increased overall costs after taking into account the off-peak increase of energy. This occurred because less supply resources are available for dispatch in non-peak hours. The large increase in energy use during off-peak hours increased prices on average by more than prices decreased during peak hours, when more supply is available to meet high levels of demand.

In all the high energy shift scenarios except for those in the South region, aggregate consumer savings from DR were less than the aggregate revenue paid to DR providers. In this situation, the DR is deployed because it passes the net benefits test during the peak hours in which the DR is dispatched, and DR providers earn revenue. However, the large increase in off-peak energy offsets consumer savings, with no corresponding decrease to DR providers' revenue. These results violate the net benefits test in principle, however they still occurred because we programmed the net benefits test in our model to be temporally myopic. By this we mean that the net benefits test did not incorporate decreased consumer welfare in future periods due to energy shifting. This myopic characteristic is also present in the ISO/RTO net benefit test methodologies in tariffs filed with FERC. FERC's final ruling in Order 745 makes no mention of incorporating effects of energy shifting in net benefits testing (U.S. FERC, 2011). Furthermore, most ISO/RTO net benefits tests in practice are characterized by econometric estimates of the monthly average price quantity pair where the supply curve becomes inelastic, with no consideration of how energy shifting from DR reduction may offset consumer savings. ${ }^{11}$ As shown by our modeling, a demand reduction that occurs at an inelastic portion of the supply curve can fail the net benefits test if consumer savings are offset by energy shifting to other periods, without a corresponding offset to DR revenue. We identify this myopic characteristic

\footnotetext{
11 MISO Net Benefits Price Threshold Information, 2017; California ISO, 2018; Southwest Power Pool, 2018; PJM 2018; New York Independent System Operator, 2011.
} 
as a policy shortcoming of the net benefits test required by FERC and operational in wholesale electricity markets across the U.S. Despite this theoretical issue identified in our modeling, we note again that this issue occurred only in our simulations with a $96 \%$ energy shift. However, while $96 \%$ is the energy shifting value assumed in EIA's Annual Energy Outlook modeling, it does not appear to be supported by empirical experimental evidence (Smith \& Brown, 2015).

\subsection{Effects not quantified}

In addition to what was quantified in this study there are other potential market effects which we do not attempt to quantify in our dynamic supply-demand framework. These include:

- Reduced generation reserve investment.

- Improved operational efficiency of the transmission and distribution systems.

- Integration of intermittent renewable generation.

- Reduced wholesale market price volatility.

- More competitive power markets.

- Insurance against extreme events.

- Improved system reliability.

- Delayed retirements of coal plants by increasing off-peak demand and reducing operational wear and tear induced by using them to follow shifts in load.

It is clear from the body of literature on the topic that the value from deploying DR programs extends across the range of actors and processes within the electricity system. Furthermore, the magnitude of these value streams varies greatly across individual markets and regulatory environments, emphasizing the need for targeted, market-specific analysis to understand the effects of implementing DR within a given market context.

\section{Conclusions}

This study quantifies consumer savings and other market effects from increasing incentivebased demand response (DR) dispatch in the Midcontinent ISO energy market. It is motivated by the fact that regulatory and market barriers in the Midcontinent region keep cost-effective DR out of the wholesale market, raising electricity prices. We develop a bottom-up, dynamic supply and demand model of the Midcontinent market that enables us to make the following conclusions:

1. DR dispatch can generate consumer savings ranging from $\$ 1.3-17.6$ million under typical peak operating conditions.

2. Model results for the South region demonstrate that consumer savings and other market effects can exponentially increase when a small amount of DR is deployed at locations with very high prices. 
3. We estimate market effects for a range of scenarios that change DR deployment levels, frequencies, and demand-shifting effects. Emissions reductions are modest but positive for most scenarios, and average price effects range from about $-\$ 0.50$ to $\$ 1.50$ per megawatt-hour across most scenarios during typical peak operations.

4. Demand response modeling can be sensitive to energy shifting assumptions. We note that the large energy shifting assumption of $96 \%$ utilized in the U.S. Energy Information Administration's National Energy Modeling Systems can produce DR deployments that violate the net benefits test once the increased post-DR consumption is accounted for. The myopic net benefits testing procedures currently used in U.S. power markets do not account for this possibility.

Our supply-demand modeling framework quantifies DR market effects due to supply curve shifts, and does not consider other market effects, including reduced or deferred capital investments, reduced price volatility, and improved system reliability. This study suggests that regulators, market operators, market participants, and other stakeholders should focus policy efforts to reduce regulatory and market rule barriers to DR deployment, particularly in locations that experience high price spikes. This will improve market efficiency and generate cost savings for electricity consumers net of system costs.

\section{Acknowledgements}

This manuscript was originally published as a working paper in January 2018 by the Great Plains Institute, and has since been revised after receiving feedback from reviewers and participants in the Colorado School of Mines Division of Economics and Business research seminar. We would also like to thank the following individuals for their review and feedback: Mike Gregerson from the Great Plains Institute, lan Lange and Ben Gilbert from the Colorado School of Mines. We also thank three anonymous referees for their thoughtful review and constructive feedback. In addition, we acknowledge and thank the Heising-Simons Foundation for their financial support.

\section{References}

Aalami, H. A., Moghaddam, M. P., \& Yousefi, G. R. (2009). Demand response modeling considering Interruptible/Curtailable loads and capacity market programs. Applied Energy, 87(1), 243-250. https://doi.org/10.1016/j.apenergy.2009.05.041

Albadi, M. H., \& El-Saadany, E. F. (2008). A summary of demand response in electricity markets. Electric Power Systems Research. https://doi.org/10.1016/j.epsr.2008.04.002 
Borenstein, S., \& Holland, S. (2005). On the efficiency of competitive electricity markets with time-invariant retail prices. RAND Journal of Economics Journal of Economics, 01(3), 469493. Retrieved from http://faculty.haas.berkeley.edu/borenste/download/Rand05RTP.pdf

Boßmann, T., \& Eser, E. J. (2016). Model-based assessment of demand-response measures-A comprehensive literature review. Renewable and Sustainable Energy Reviews, 57, 16371656. https://doi.org/10.1016/j.rser.2015.12.031

Braithwait, S. D., \& Eakin, K. (2002). The role of demand response in electric power market design. Edison Electric Institute, (October). Retrieved from http://www.smartgridnews.com/artman/uploads/1/sgnr_2007_12014.pdf

Bushnell, J., Hobbs, B. F., \& Wolak, F. A. (2009). When It Comes to Demand Response, Is FERC Its Own Worst Enemy? Electricity Journal, 22(8), 9-18. https://doi.org/10.1016/j.tej.2009.08.004

Buzoianu, M., Brockwell, A., \& Seppi, D. (2005). A dynamic supply-demand model for electricity prices. Carnegie Mellon University Department of Statistics Working Paper. Retrieved from http://repository.cmu.edu/statistics/134

California Independent System Operator. (2018). Demand response net benefits test. Retrieved from

http://www.caiso.com/informed/Pages/StakeholderProcesses/CompletedClosedStakehold erlnitiatives/DemandResponseNetBenefitsTest.aspx

Cappers, P., Goldman, C., \& Kathan, D. (2010). Demand response in U.S. electricity markets: Empirical evidence. Energy, 35(4), 1526-1535. https://doi.org/10.1016/j.energy.2009.06.029

Cappers, P., MacDonald, J., Goldman, C., \& Ma, O. (2013). An assessment of market and policy barriers for demand response providing ancillary services in U.S. electricity markets. Energy Policy, 62, 1031-1039. https://doi.org/10.1016/j.enpol.2013.08.003

Chao, H., \& DePillis, M. (2013). Incentive effects of paying demand response in wholesale electricity markets. Journal of Regulatory Economics, 43(3), 265-283. https://doi.org/10.1007/s11149-012-9208-1

Chen, X., \& Kleit, A. N. (2016). Money for Nothing? Why FERC Order 745 Should have Died. The Energy Journal, 37(2). https://doi.org/10.5547/01956574.37.2.xche

Dahlke, S. (2018). Data and code for "Consumer savings, price, and emissions impacts of increasing demand response in the Midcontinent electricitt market." Open Science Framework. Retrieved from https://osf.io/6r5cw/ 
De Jonghe, C., Hobbs, B. F., \& Belmans, R. (2012). Optimal generation mix with short-term demand response and wind penetration. IEEE Transactions on Power Systems, 27(2), 830839. https://doi.org/10.1109/TPWRS.2011.2174257

Economics, P. (2017). 2016 State of the Market Report for the MISO Electricity Markets. Retrieved from https://www.misoenergy.org/Library/Repository/Report/IMM/2016 State of the Market Report.pdf

Eldali, F., Hardy, T., Corbin, C., Pinney, D., \& Javid, M. (2016). Cost-benefit analysis of Demand Response programs incorporated in Open Modeling Framework. In IEEE Power and Energy Society General Meeting. Boston. https://doi.org/10.1109/PESGM.2016.7741264

Eryilmaz, D., Smith, T. M., \& Homans, F. R. (2017). Price Responsiveness in Electricity Markets: Implications for Demand Response in the Midwest. The Energy Journal, 38(1). https://doi.org/10.5547/01956574.38.1.dery

Faruqui, A., Hajos, A., Hledik, R. M., \& Newell, S. A. (2009). Fostering economic demand response in the Midwest ISO. Energy, 35(4), 1544-1552. https://doi.org/10.1016/j.energy.2009.09.014

Faruqui, A., \& George, S. S. (2002). The value of dynamic pricing in mass markets. Electricity Journal, 15(6), 45-54. https://doi.org/10.1016/S1040-6190(02)00330-5

Faruqui, A., Hledik, R., Newell, S., \& Pfeifenberger, H. (2007). The Power of 5 Percent. Electricity Journal, 20(8), 68-77. https://doi.org/10.1016/j.tej.2007.08.003

Hogan, W. W. (2010). Demand Response Compensation, Net Benefits and Cost Allocation: Comments. The Electricity Journal, 23(9), 19-24. https://doi.org/10.1016/J.TEJ.2010.10.002

Holland, S. P., \& Mansur, E. T. (2006). The Short-Run Effects of Time-Varying Prices in Competitive Electricity Markets. The Energy Journal, 27(4). https://doi.org/10.5547/ISSN0195-6574-EJ-Vol27-No4-6

Kahn, A. E. (2010). Affidavit, Demand Response Compensation in Organized Wholesale Markets. U.S. Federal Energy Regulatory Commission.

Lau, E. T., Yang, Q., Stokes, L., Taylor, G. A., Forbes, A. B., Clarkson, P., ... Livina, V. N. (2015). Carbon savings in the UK demand side response programmes. Applied Energy, 159, 478489. https://doi.org/10.1016/j.apenergy.2015.08.123

Leautier, T.-O. (2014). Is Mandating "Smart Meters" Smart? The Energy Journal. Retrieved from https://www.iaee.org/en/publications/ejarticle.aspx?id=2851 
Lovins, A. B. (1985). Saving gigabucks with negawatts. Public Utility Fortnightly, 115:6. Retrieved from https://www.fortnightly.com/fortnightly/1985/03/saving-gigabucks-negawatts-1985

Malabonga, D. M., \& Counsel, A. G. C. (2017). Midcontinent Independent System Operator, Inc. Compliance Filing for Order 831. Retrieved from https://elibrary.ferc.gov/idmws/file_list.asp?document_id=14569982

McAnany, J. (2016). 2015 Demand Response Operations Markets Activity Report: May 2016. Retrieved from http://www.pjm.com/-/media/markets-ops/dsr/2015-demand-responseactivity-report.ashx?la=en

Midcontinent Independent System Operator. (2017). Net Benefits Price Threshold Information. Retrieved from https://old.misoenergy.org/Library/Repository/Report/Demand Response/Net Benefits Price Threshold.pdf

Midcontinent Independent System Operator. (2016). Business Practice Manual 010-r11 Sections 3.1.1.4 \& 3.1.1.5. Retrieved from https://www.misoenergy.org/library/businesspracticesmanuals/Pages/BusinessPracticesM anuals.aspx

Midcontinent Independent System Operator. (2017). Tariff Module C Energy and Operating Reserve Markets.

Midcontinent Independent System Operator. (2017). LMR Performance During April 4th, 2017 Maximum Generation Event. Retrieved December 22, 2017, from https://www.misoenergy.org/Library/Repository/Meeting Material/Stakeholder/MSC/2017/20170713/20170713 MSC Item 07 LMR Deployment Clarification.pdf

Midcontinent Independent System Operator. (2017). Business practices manual: Resource adequacy. Retrieved from

https://www.misoenergy.org/_layouts/MISO/ECM/Redirect.aspx?ID=19206

Midcontinent Independent System Operator. (2015). Real-time fuel on the margin. Retrieved from https://www.misoenergy.org/Library/MarketReports/Pages/MarketReports.aspx

Midcontinent Independent System Operator. (2016). Planning Resource Auction. Retrieved from

https://www.misoenergy.org/PLANNING/RESOURCEADEQUACY/Pages/RAContruct.aspx

Midcontinent Independent System Operator. (2014). MISO zones: Presentation to the Supply Adequacy Working Group. 
Midcontinent Independent System Operator. (2015). Historical regional forecast and actual load. Retrieved from https://www.misoenergy.org/Library/MarketReports/Pages/MarketReports.aspx

Midcontinent Independent System Operator. (2015). Real-time pricing report. Retrieved from https://www.misoenergy.org/Library/MarketReports/Pages/MarketReports.aspx

Midcontinent Independent System Operator. (2015). Real-time cleared offers. Retrieved from https://www.misoenergy.org/Library/MarketReports/Pages/MarketReports.aspx

New York Independent System Operator. (2011). NYISO Demand Response Net Benefits Test. Retrieved from http://www.nyiso.com/public/webdocs/markets_operations/market_data/demand_respo nse/Demand_Response/Monthly_Net_Benefit_Offer_Floor/Compliance_Filing_Data/Net_ Benefits_Test_Description-compliance_filing.pdf

PJM. (2014). PJM Demand Side Response Overview. Retrieved from https://www.pjm.com/ /media/training/pjm-demand-side-response-overview-v2.ashx

Potomac Economics. (2017). 2016 State of the Market Report for the MISO Electricity Markets.

Rivers, N., \& Jaccard, M. (2011). Electric Utility Demand Side Management in Canada. The Energy Journal, 32(4). https://doi.org/10.5547/ISSN0195-6574-EJ-Vol32-No4-5

Schweppe, F. C., Caramanis, M. C., Tabors, R. D., \& Bohn, R. E. (1988). Spot Pricing of Electricity. Springer U.S.

Smith, A. M., \& Brown, M. A. (2015). Demand response: A carbon-neutral resource? Energy, 85, 10-22. https://doi.org/10.1016/j.energy.2015.02.067

Southwest Power Pool. (2018). Net Benefits Test. Retrieved from https://www.spp.org/markets-operations/net-benefits-test/

Taylor, T. N., Schwarz, P. M., \& Cochell, J. E. (2005). 24/7 Hourly response to electricity real-time pricing with up to eight summers of experience. Journal of Regulatory Economics, 27(3), 235-262. https://doi.org/10.1007/s11149-005-6623-6

The Brattle Group. (2007). Quantifying Demand Response Benefits in PJM. Retrieved from http://brattle.com/system/publications/pdfs/000/004/917/original/Quantifying_Demand_ Response_Benefits_in_PJM_Jan_29_2007.pdf?1379343092

The Cadmus Group, I. (2009). Process evaluation of Xcel Energy's Saver's Switch program. Retrieved from https://www.xcelenergy.com/staticfiles/xe/Regulatory/Regulatory PDFs/DSM-Evaluation-Savers-Switch.pdf 
U.S. Department of Energy. (2016). Environment Baseline, Volume 1: Greenhouse Gas Emissions from the U.S. Power Sector.

U.S. Department of Energy. (2006). Benefits of Demand Response in Electricity Markets and Recommendations for Achieving Them. Retrieved from https://energy.gov/sites/prod/files/oeprod/DocumentsandMedia/DOE_Benefits_of_Dema nd_Response_in_Electricity_Markets_and_Recommendations_for_Achieving_Them_Repo rt_to_Congress.pdf

U.S. Energy Information Administration. (2017). Annual Energy Outlook 2017: Availability of the National Energy Modeling System (NEMS) Archive. Retrieved from https://www.eia.gov/outlooks/aeo/info_nems_archive.php

U.S. Energy Information Administration. (2014). Form EIA-861 Annual Electric Power Industry Report Instructions.

U.S. Energy Information Administration. (2016). Electric power sales, revenue, and energy efficiency Form EIA-861 detailed data files. Retrieved from https://www.eia.gov/electricity/data/eia861/

U.S. Federal Energy Regulatory Comission. (2017). Order on Compliance 61,155. Retrieved from https://www.ferc.gov/CalendarFiles/20171109172524-ER17-1570-000.pdf

U.S. Federal Energy Regulatory Comission. Midcontinent Independent System Operator Order 831 Compiance Order, Docket No. ER17-1570-000, Pub. L. No. 161 FERC 61,155 (2017). United States of America.

U.S. Federal Energy Regulatory Comission. (2010). The DRIVE Model. Retrieved January 1, 2017, from https://www.ferc.gov/industries/electric/indus-act/demand-response/drpotential/action-plan.asp

U.S. Federal Energy Regulatory Comission. (2009). A National Assessment of Demand Response Potential. https://doi.org/10.1017/CBO9781107415324.004

U.S. Federal Energy Regulatory Comission. (2011). Order No. 745: Demand Response Compensation in Organized Wholesale Energy Markets. Retrieved from https://www.ferc.gov/EventCalendar/Files/20110315105757-RM10-17-000.pdf

Wellinghoff, J., \& Morenoff, D. L. (2007). Recognizing the Importance of Demand Response: The Second Half of the Wholesale Electric Market Equation. Energy Law Journal, 28(2), 389419.

Wirl, F. (2000). Lessons from utility conservation programs. Energy Journal, 21(1), 87-108. https://doi.org/10.2307/41322856 